Library Management, 2002, Vol. 23 Iss: 6/7, pp.325 - 329.

ISSN: 0143-5124

DOI: $10.1108 / 01435120210432291$

http://www.emeraldinsight.com/

http://www.emeraldinsight.com/journals.htm?issn=0143-5124

http://www.emeraldinsight.com/journals.htm?issn=0143-

$5124 \&$ volume $=23 \&$ issue $=6 \&$ articleid $=859054 \&$ show $=\mathrm{html}$

(c) 2002 MCB UP Ltd

\title{
Outsourcing of Slavic cataloguing at the Ohio State University libraries: evaluation and cost analysis
}

\author{
Magda El-Sherbini
}

\begin{abstract}
Examines the outsourcing of Slavic original cataloguing at the Ohio State University libraries. It includes: the rationale for doing so; the evaluation and cost analysis; the advantages and disadvantages; and what we have learned.
\end{abstract}

\section{Introduction}

An earlier paper provided a case study of copy cataloguers and their changing roles at the Ohio State University Library (El-Sherbini, 2001). This paper was developed from a presentation by the author at the Ohio Library Council Annual Meeting held in Columbus, Ohio in November 2000.

In 1994, the Ohio State University libraries conducted a study on the viability of outsourcing of the original cataloguing of Slavic books. The results of this study were analysed in an article entitled "Contract cataloging: a pilot project for outsourcing Slavic books" (El-Sherbini, 1995). At that time the Slavic backlog consisted of approximately 25,000 titles in all formats. Based on this analytic study, which proved at that time that the outsourcing was more cost effective than hiring an MLS cataloguer, the decision was made to contract out the original cataloguing of this Slavic backlog. After six years of the Slavic original cataloguing being undertaken by the vendor, it is now time to evaluate the process to determine:

- if it is still cost effective;

- if there are other options available;

- if there is new in-house funding for cataloguing;

- if the library is not satisfied with the vendor service;

- if the library developed in-house expertise; and

- if the library has reorganised its operations and found a way to utilize expertise from other departments.

Hence, this paper examines the outsourcing of Slavic original cataloguing at the Ohio State University libraries. It reviews: 
- the rationale for so doing;

- the evaluation;

- the advantages and disadvantages; and

- what we have learned.

\section{Rationale}

In a previous study (El-Sherbini, 1995), the rationale for contracting out the Slavic original cataloguing was summarised in the following points:

- resignation of the Slavic languages original cataloguer in April 1993;

- a backlog of Slavic materials, about 25,000 titles in various Slavic languages and in various formats;

- budget uncertainties; and

- change to a new in-house system (OSCAR).

After studying several methods of obtaining original cataloguing records, the decision was made to conduct a pilot project and send 100 Slavic titles (monographic materials only) to OCLC TechPro. The goals of this pilot project were to test the quality of records obtained from a vendor, and compare the cost for cataloguing in-house versus outsourcing. The study proved that the quality of records obtained by the vendor was acceptable and the price was reasonable. This step was followed by writing the actual contract specifications and starting to send 65 monographic titles to OCLC to be catalogued originally.

\section{Evaluation and cost analysis of the contract}

\section{Statistical information}

After five years of contracting out the Slavic original cataloguing, now it is time to reassess and evaluate this process. In order to do the assessment, some statistical information is needed.

The Slavic backlog was divided into a historic backlog and new receipts backlog in addition to the current new receipts (acquisition) materials.

(1) Historic backlog information from November 1994 to September 2000:

- Number of titles in the historic backlog in $1994=25,000$ titles.

- Number of titles catalogued by OCLC TechPro 1994-2000 = 2,508 titles (original cataloguing).

- Number of titles catalogued by OSU staff from the historic backlog=18,706 titles (copy and original cataloguing). (This cataloguing was done by twi Slavic GAs and student assistants.)

- Total catalogued titles from the historic backlogs 21,214 titles.

- Remaining uncatalogued titles from the historic backlog $=3,786$ titles. 
(2) New receipts backlog catalogued by OSU staff in 1994-2000 = 5,000 titles.

(3) Current new receipts (acquisition) catalogued by OSU staff in 1994-2000 = 11,246 titles.

(This cataloguing is done by the two Slavic GAs and student assistants):

- Total of titles catalogued in-house from November 1994 to September $2000=18,706+$ $5000+11,246=34,952$ titles (copy and original cataloguing).

- Total of titles catalogued by OSU staff and TechPro from November 1994 to September $2000=37,460$ (copy and original).

The following is a description of the catalogued titles by material types:

- book: 35,707;

- serial: 958;

- manuscript: 201;

- music score: 200;

- printed map: 192;

- $\mathrm{A} / \mathrm{V}: 17$;

- music record: 182 ;

- computer file: one;

- OSU thesis: one; and

- non-music record: one.

\section{Cost analysis}

In this section, the author will discuss the cost of cataloguing using the vendor versus the cost of cataloguing in-house. Some of the figures, such as the support cost, will be estimated. The cost of using in-house staff is based on the monthly and/or annual salary with benefits.

\section{OCLC TechPro cost analysis}

- $\quad$ Cost of the 2,508 catalogued titles $=\$ 76,140.65$.

- Support costs[1] = $\$ 15,831$.

- Total cataloguing cost $=$ OCLC TechPro cost + the support. $\operatorname{cost}=\$ 76,140.65+15,831=$ $\$ 91,971.65$

- $\quad$ Cost by OCLC TechPro per title $=\$ 91,971.65$ divided by 2,508 titles $=\$ 36.67$ per title (the average for original cataloguing).

\section{Cataloguing cost in-house}

- Total of titles catalogued in-house from November 1994 to September $2000=34,952$ copy and original (about 20 per cent original $=6,990$ original titles and 80 per cent copy $=27,962$ titles).

- $\quad$ Staff and students costs for cataloguing these materials [1,2] $=\$ 210,993.46$.

- Original cataloguing credit $=6,967$ titles $x \$ 4$ (average) $=827,868$.

- $\quad$ Net cost $=\$ 210,993.46-527,868=\$ 183,125.46$. 
- $\quad$ Cost per title $($ copy and original $)=\$ 183,125.46$ divided by 34,952 titles $=\$ 5.23$.

- To calculate the cost per original title, an assumption was made that about 65 per cent of the staff time $(\$ 183,125.46)$ was spent to perform this function $=\$ 119,035.49$ divided by 6,990 titles $=\$ 17.03$.

- To calculate the cost per copy cataloguing title, an assumption was made that about 35 per cent of the staff time $(\$ 183,125.46)$ was spent on this function $=\$ 64,089.97$ divided by 27,869 titles $=\$ 2.29$.

\section{Conclusion of the cost analysis}

From the above cost analysis you will note that in 2000 the cost of doing original cataloguing in-house was \$17.03 and the cost of contract cataloguing is \$36.67 per title. In 1994 the cost of undertaking the original cataloguing in-house was $\$ 56.32$ per title and for contact cataloguing it was $\$ 34.71$ (El-Sherbini, 1995). The reasons for lowering the cost of cataloguing in-house were:

- Shifting original cataloguing responsibilities to staff, GAs and student assistants. This enabled the department to focus more on the cataloguing and eliminated a great deal of the time that the professional cataloguers were spending on other professional activities (e.g. committees, publications, national involvement, etc.).

- Streamlining the workflow by eliminating the redundancies such as the first and second searches.

- Eliminating the complexity of the workflow, and the difficulty of moving materials from one room to another, and from one person to another. This is eliminated by consolidating the cataloguing function in one room and creating teamwork to handle the cataloguing operations from A-Z. The teamwork eliminated several steps, and reduced time wasted in terms of problem-solving and answering questions.

- Eliminating the backlog. The items are handled once and never returned to the backlog for someone else to do the work.

- Increasing the number of workstations. Everyone in the cataloguing department now has his/her own workstation. This eliminated the amount of time spent waiting for a free terminal.

- Cataloguing documentation is now available on the Web which makes it more efficient and up-to-date.

- Moving an in-house technical services IT person made it more efficient for trouble shooting to happen immediately.

The vendor price for cataloguing remains high because once you start at a certain price for cataloguing per title, you will not be able to lower this price. Instead, every year the price increases slightly.

Cataloguing in-house still requires extensive training especially with students and graduate student assistants (GSA).

\section{Advantages and disadvantages of contract cataloguing}

\section{Advantages}

(1) Outsourcing is used as a means to reduce backlogs, increase productivity, and allow for shifts 
in staff.

(2) Outsourcing is used to gain expertise in foreign languages that is not available from the local staff.

(3) It opens our eyes to other methods of cataloguing in-house for example:

- reducing redundancy in handling each item;

- $\quad$ simplifying the workflow;

- using paraprofessionals in cataloguing; and

- $\quad$ using graduate students and student assistants in cataloguing

(4) The vendor's focus is only on cataloguing: there is no involvement in submitting name authority records to NACO; less time is spent on searching bibliographical sources beyond the OCLC database to support the form of heading.

(5) The vendors have greater flexibility in moving personnel according to their needs.

(6) Compared to libraries' workflow, their workflow is more efficient. Since they must keep current with their workflow because of specific deadlines for their customers, they do not encounter the problems and expenses involved in managing a backlog.

(7) Keeping current with, and distributing information about, cataloguing rules takes less time with fewer people.

(8) Some original cataloguing is done by experienced paraprofessionals who generally are employed at salaries that are lower than those of professionals.

(9) The vendors are mostly cataloguing according to the customer's specifications; hence, no time is spent in negotiating changes in procedures or in decision-making.

\section{Disadvantages}

(1) Outsourcing has proven not to be cost effective.

(2) The quality of cataloguing can be vary from time to time based on who the vendor is hiring, and the level of expertise.

(3) Hiring graduate students and student assistants to do cataloguing in-house could be time consuming and problematic since it does not provide stability, and training could be a major issue. In this case, contract cataloguing can be a good solution; alternatively hiring permanent staff to do cataloguing in-house could be more economical and more effective.

(4) It is very difficult for the vendor to keep the cataloguing quota as stated in the agreement. This can cause a problem in terms of controlling the backlog and planning on when it will be eliminated.

(5) The outsourcing price can rise and there is no flexibility in reducing the price unless you 
change vendors.

(6) Sometimes, you spend a great deal of time to fix or solve cataloguing problems in-house.

(7) Communicating problems to the vendor can be time consuming.

\section{What we have learned and the conclusion}

Contracting can be viewed as a remote extension of technical services and sometimes is the only option. It might not solve all of the problems and it can be time consuming and frustrating. Outsourcing, however, is not a threat to the professional cataloguers. If you do it right, outsourcing might be rewarding for the library.

\section{Notes}

1. See details of support costs in Appendix 1.

2. See details of staff costs in Appendix 2.

3. Data used to calculate the costs of using in-house staff are based on actual staffing, which fluctuated throughout the five-year period.

\section{References}

El-Sherbini, M. (1995), "Contract cataloging: a pilot project for outsourcing Slavic books", Cataloging \& Classification Quarterly, Vol. 20 No. 3, pp. 57, 64-6.

El-Sherbini, M. (2001), "Copy cataloguers and their changing roles at the Ohio State University Library: a case study", Library Management, Vol. 22 No. 1 and 2, pp. 80-5.

\section{Appendix 1}

\section{OCLC support cost}

Retrieving books from the backlog:

1 hour of a GAA $=1 \times \$ 9.80=\$ 9.80$.

Searching 65 titles in OCLC:

5 hours of GAA time $=5 \times \$ 9.80=\$ 49$.

Cost for in-house searching:

65 titles $\times 30$ cents $=\$ 19.50$.

Searching the local system to discharge books from the backlog, charge to OCLC TechPro and create the inventory lists:

3 hours of a students time $=3 \times \$ 5=\$ 15$.

Packing the books in boxes:

2 hours of students time $=2$ hours $x \$ 5=\$ 10$.

Sending the books to OCLC TechPro $=\$ 15$ UPS.

Reviewing the returned books against the inventory list and checking the books in the OSU local system to make sure that every book had been returned and was in the system:

4 hours of student time $=4 \times \$ 5=\$ 20$. 
Spot-checking:

3 hours by the Slavic

$\mathrm{GAA}=3 \times \$ 9.80=\$ 29.40$.

Managing the project, solving problems, and answering questions (locally or with OCLC

TechPro):

5 hours of faculty

time $=5 \times$ x $\$ 19.23=196.15$.

Total support cost per month $=\$ 263.85$.

Total support cost for five years:

$\$ 263.85 \times 60$ months $=\$ 15,831$.

\section{Appendix 2}

Staff cost for cataloguing these materials [3]:

Graduate Student Assistants

$(\mathrm{GAA})=2 \times \$ 10,200$ a year $=\$ 20,400 \times 5$ years $=\$ 102,000$

Student assistant $=40$ hours a week $\times \$ 5$ average per hour $=\$ 200 \times 52$ weeks $=\$ 10,400 \times 3$ years $=\$ 31,200$. Slavic staff $=\$ 90,847.8$ for three years and 70 per cent were only devoted to cataloguing Slavic $=\$ 63,593.46$. Slavic staff $=\$ 21,000$ for one year and 20 per cent was devoted to cataloguing Slavic $=\$ 4,200$.

Faculty supervisor $=$ average salary in 5 years $=\$ 200,000 \times 5$ per cent spent on this project $=$ $\$ 10,000$.

(This includes problem solving and training GAs and student assistants in addition to catalogue maintenance.) 